\title{
RENAL SARCOMA - A RARE PARENCHYMAL TUMOR WITH A VERY POOR PROGNOSIS
}

\author{
Lucian IORGA ${ }^{1}$, Radu ANGHEL ${ }^{1}$, Dragos MARCU ${ }^{1,2} \bowtie$, Dan SPINU ${ }^{1,2}$, Anca PANTEA STOIAN ${ }^{3}$, \\ Camelia DIACONU ${ }^{4}$, Elvira BRATILA ${ }^{5}$, Bogdan SOCEA ${ }^{6}$, Tiberiu P. NEAGU, \\ Dan MISCHIANU1,2,7, Ovidiu BRATU1,2,7
}

${ }^{1}$ Clinic of Urology, University Emergency Central Military Hospital „Dr. Carol Davila“, Bucharest, Romania

${ }^{2}$ University of Medicine and Pharmacy „Carol Davila“, Clinical Departament 3, Bucharest, Romania

${ }^{3}$ Department of Diabetes and Nutrition, "Carol Davila" University of Medicine and Pharmacy, Bucharest, Romania

${ }^{4}$ „Carol Davila“ University of Medicine and Pharmacy, Clinical Emergency Hospital of Bucharest, Romania 5 "Carol Davila“"University of Medicine and Pharmacy, Clinic of Obstetrics and Gynecology, „Panait Sarbu“ Hospital, Bucharest, Romania

${ }^{6}$ „Carol Davila“ University of Medicine and Pharmacy, General Surgery Clinic, Emergency Clinical Hospital "Sfântul Pantelimon", Bucharest, Romania

${ }^{7}$ Academy of Romanian Scientists

Received 29 June 2018, Accepted 14 Aug 2018 hitps://doi.org/10.31688/ABMU.2018.53.3.20

\begin{abstract}
The aim of this paper was to analyze the prognostic features, clinical presentation, diagnosis and treatment of primary renal sarcomas. A thorough review of the literature was made using the PubMed database. Sarcomas of the kidney are very rare malignant tumors, with a very poor prognosis compared with the other urogenital sarcomas. Several histological types have been reported, with the most common type being leiomyosarcoma. Besides complete surgical resection with wide margins, anatomical, histological, molecular and genetic factors should be taken into consideration regarding the prognosis.
\end{abstract}

\section{Résumé}

Le sarcome rénal - une tumeur parenchymateuse rare avec un pronostic très mauvais

Le but de cet article était d'analyser les caractéristiques pronostiques, la présentation clinique, le diagnostic et le traitement des sarcomes rénaux primaires. Une revue approfondie de la littérature a été réalisée à l'aide de la base de données PubMed. Les sarcomes du rein sont des tumeurs malignes très rares, avec un très mauvais pronostic par rapport aux autres sarcomes urogénitaux. Plusieurs types histologiques ont été rapportés, le type le plus courant étant le léiomyosarcome. Outre la résection chirurgicale complète à larges marges, des facteurs anatomiques, histologiques, moléculaires 
Keywords: sarcoma, kidney, prognosis, histopathological, genetic, molecular.

\section{INTRODUCTION}

Renal sarcomas account for 1 to $3 \%$ of malignant kidney tumors, being diagnosed predominantly in the $5^{\text {th }}$ or $6^{\text {th }}$ decade of life $e^{1}$. In the kidneys, there are different types of mesenchymal cells that create the potential for various histologic types of sarcoma. The most common type of sarcoma is leiomyosarcoma (LMS), accounting for $50-60 \%$ of cases $^{1}$. LMS are solitary lesions, usually highly aggressive, that are usually more common in females, occurring in the $4^{\text {th }}$ and $6^{\text {th }}$ decade of life ${ }^{1}$. Similar to their benign counterpart (leiomyomas), kidney LMSs can originate from the smooth muscles of the renal pelvis, calyxes, renal capsule and blood vessels, most commonly from the smooth muscle layers of the renal veins ${ }^{1}$. Regarding the frequency, LMSs are followed by liposarcomas in $10-15 \%$ of cases ${ }^{2}$. Additional histological subtypes include osteogenic sarcoma, rhabdomyosarcoma (RMS), fibrosarcoma, carcinosarcoma, synovial sarcoma, angiosarcoma, anaplastic sarcoma, malignant fibrous histiocytoma, myeloid sarcoma, malignant hemangiopericytoma, interdigitating dendritic cell sarcoma (IDCS), Ewing's sarcoma, and primitive neuroectodermal tumor (PNET). These tumors are avascular lesions, with the exception of angiosarcomas ${ }^{2}$.

Sarcomas typically possess a pseudocapsule, which is not a reliable barrier from the surgical point perspective, often being infiltrated by the tumor. Sarcomas of the kidney can expand and reach large sizes, due to the lack of natural barriers for tumors arising from the mesenchymal components ${ }^{3}$.

Renal sarcomas are less frequently observed, compared with other types of urogenital sarcomas, such as those of the prostate and bladder, having a poorer prognosis in terms of survival and a lower life expectancy. For example, Lee et al found that the five-year survival rate for renal sarcomas was 39\%, while the same survival rate in retroperitoneal sarcoma was $82 \%, 73 \%$ in patients with bladder sarcoma and $44 \%$ in patients with prostate sarcoma ${ }^{4}$. The biological behaviors of renal and other soft tissues sarcomas are unpredictable and the disease is known to be associated with a poor prognosis and a high metastatic potential $1^{4}$. The five-year survival rate, according to Geonseok, in all the urogenital sarcomas, was on average $51.4 \%{ }^{5}$. There are two studies in the et génétiques doivent être pris en compte en ce qui concerne le pronostic.

Mots-clés: sarcome, rein, pronostic, histopathologique, génétique, moléculaire.

literature that support these findings, reporting a mean survival around $50 \% 5,6$.

Usually, renal sarcomas evolve asymptomatically. The tumor becomes symptomatic with the expansion of its size, symptoms increasing with advancing disease. The presenting features may include abdominal mass, lumbar or abdominal pain, and hematuria. Pain may result because of tumor size, compression on the neighboring tissues (liver, lungs, colon, blood vessels), necrosis within the tumor, passage of a blood clot through the collecting system? ${ }^{7}$. Hematuria occurs as a result of renal collecting system invasion. These patients can also develop ureterohydronephrosis with acute or chronic renal failure which may impose the dialysis ${ }^{8,9,10}$. Other important complications that may arise secondary to the urinary tract obstruction are hydroelectrolytic imbalances such as hyponatremia and hyperkalemia ${ }^{11,12}$. These imbalances can leadto important cardiovascular complications such as arrhythmias and even to cardiovascular arrest $\mathrm{t}^{13,14,15}$. Systemic symptoms, such as fever, nausea, vomiting, anemia, weight loss, malignant hypertension, cough, hemoptysis, coagulation disturbances can also occur ${ }^{16,17}$. These symptoms can be explained by the compression or tumoral extension in the nearby organs and can be secondary to numerous other kidney or retroperitoneal tumors ${ }^{18-20}$.

To summarize, the clinical signs of presentation are those of a large renal carcinoma, thus being extremely challenging to differentiate renal sarcomas from renal cell cancer. The most important features that differentiate sarcomas from renal cell cancer are that sarcomas originate from the mesenchymal cells of the capsule or perisinous region and expand to large sizes without lymphadenopathy. The sarcomas should definitely be considered in the differential diagnosis in the presence of fast-growing renal masses. Extension to the renal vein and inferior vena cava may occur.

Macroscopically, sarcomas are predominantly large solid tumors, with variable consistency, shiny gray-white appearance on the surface of the section, with extensive areas of necrosis and bleeding.

The American Joint Committee on Cancer (2010) revealed that the prognosis of soft-tissue sarcomas was directly associated with the disease stage ${ }^{21}$. 


\section{Anatomical AND SURgical Factors}

Surgical resection and the stage of the tumor are the most important prognostic factors in patients with renal sarcoma. Lewis et al reported that an unrespectable tumor or an incomplete surgical resection were the most significant factors associated with disease-specific mortality ${ }^{22}$. A study on 143 patients, conducted by Delan et al, concluded that complete tumor resection with large margins was associated with improved overall survival, due to the presence of reactive tissue surrounding the tumor with high risk of local recurence ${ }^{23}$.

In cases of high-grade sarcoma, high doses of radiotherapy are needed, but its toxic effects on other organs limit the dose of radiotherapy, and therefore complicates the control of the disease ${ }^{24}$.

The presence of metastasis at the time of diagnosis is a significant prognostic factor, as survival rate is usually shorter in these patients, statement strongly supported by the study conducted by Lee et $\mathrm{al}^{4}$. Most common sites of metastasis include: lungs, liver and colon.

A thorough review of the literature reveals that surgical resection is the only prognostic factor able to confer increased survival rates in patients with a primary tumor, or in those with a metastatic disease, and that the inability to perform surgical resection appears to be the most unfavorable prognostic variable for overall survival ${ }^{4}$.

Valery et al found that a tumor size smaller than $5 \mathrm{~cm}$ is associated with a favorable prognosis ${ }^{3}$. In a study conducted by Hakan et al, 2 out of 10 patients enrolled in the research had a tumor measuring less than $5 \mathrm{~cm}$, and they achieved the highest survival rate $^{25}$.

It is known that adjuvant/neoadjuvant chemotherapy/radiotherapy do not provide significant survival advantages. Nagumo et al administered systemic chemotherapy with gemcitabine and docetaxel in a 64-year-old patient with renal LMS and lung metastasis, and obtained an incomplete response in the lung metastasis. However, the patient developed new metastases in the lungs and pancreas at the end of 29 months. This study is one of the rare reports in the literature that demonstrated the survival benefit of chemotherapy, particularly therapy with gemcitabine and docetaxel ${ }^{26}$.

In a research coordinated by Kamba et al, it has been reported that LMS could become resectable with the administration of neoadjuvant chemotherapy with CYVADIC (cyclophosphamide, vincristine, adriamycin, and dacarbazine $)^{27}$.

Local recurrence is a common feature of renal sarcomas, but with poor response to chemotherapy and with no established chemotherapy protocol, disease recurrence, particularly following the administration of chemotherapy, is associated with a poor prognosis $^{28}$.

An important prognostic factor, that has a negative impact on the survival rate, is the involvement of regional lymphnodes. Although extremely rare in cases of renal sarcoma, certain subtypes of renal sarcomas, such as high-grade RMS, angiosarcoma, clear cell sarcoma and epithelioid sarcoma are more likely to spread to the lymph nodes ${ }^{29}$.

\section{Histopathological factors}

The number of mitoses, the degree of cellularity, the cellular and nuclear morphology, the presence of necrosis, all contribute in establishing the histological grade of the tumor, which is able to describe the metastatic potential of the sarcoma. Low-grade mesenchymal tumors exhibit limited metastatic potential, but tend to recur locally.

Increased rates of necrosis, poor differentiation, mitotic activity and increased histological grade are associated with a poor prognosis. In their research, Deyrup et al revealed the relationship between increasing histological grade of LMS and the rate of survival. The histological grade was described as a poor prognostic factor ${ }^{30}$.

Renal myeloid sarcoma, originating from leukemia cells, has the potential to transform into acute myeloid leukemia. These types of sarcomas have a higher chance of being sensitive to chemotherapy. Kidney sarcomas that are sensitive to chemotherapy are associated with a favorable prognosis ${ }^{31}$.

Synovial sarcoma is a highly malignant neoplasm, having a high metastasis potential, thus being associated with a poor prognosis. The tumor, however, is regarded to be sensitive to anthracycline-based chemotherapy, with a response rate of $53 \%{ }^{31}$. In literature, only 60 cases of synovial sarcomas have been reported.

Ewing's sarcoma and PNET of the kidney are rare, high grade tumors, with only over 100 cases globally, which typically appear in children, adolescents and young adults. Renal PNET is the predominant type of aggressive kidney sarcoma, that occurs in males, aged $28-34$ years old, often characterized by early metastatic potential ${ }^{32,33}$.

Renal IDCS is an extremely rare malignant tumor, originating from dendritic cells, that primarily occurs in the lymph nodes. The pathogenesis of kidney IDCS is strongly associated with the chromosomal translocation of the B-cell lymphoma 2 protein $^{34,35}$.

High grade renal RMS are very aggressive tumors with high metastatic potential, with a tendency 
for regional lymphnodes. The value of the histological type regarding the prognosis is still unclear. In a research conducted by Lee et al, it has been reported that the histological subtype of the renal sarcoma was not defined as a prognostic factor for disease-specific survival in the univariate and multivariate analyses ${ }^{4}$.

\section{Genetic And molecular factors}

Renal sarcomas are known to be genetically complex, frequently showing "chaotic" karyotypes, such as aneuploidy and polyploidy. Studies have shown that the p16 and p53 tumor suppressor proteins are overexpressed in LMS, therefore they could be used as prognostic markers ${ }^{36}$.

The Mediator complex is a multi-subunit assembly required for regulating expression of most RNA polymerase II transcripts, with a key role in eukaryotic gene transcription activation. Subunit 12 homo$\log$ (MED12) regulates the activity of the complex. Mutations occurring at this location are presumed to represent the basic mechanisms involved in the development of kidney sarcomas. These mutations have been found in uterine leiomyomas, as well as in pelvic and retroperitoneal LMS, suggesting that different smooth muscle tumors develop as a result of similar mutagenic changes ${ }^{37}$.

A great number of genomic alterations have been found with significant impact on the prognosis of the disease. Deletions in the $4 \mathrm{q} 31$ and $18 \mathrm{q} 22$ regions have been associated with a high metastasis potential and the duplication at 1q21.3 has been identified as an independent prognostic factor for shorter survival times in patients with LMS. On the other hand, a 17q duplication is associated with a long-term disease-free survival and a low risk of metastasis and 1p33-p32.3 duplications were correlated with increased survival rates $^{3,38}$

Another genetic mutation suspected to be involved in the pathogenesis of renal LMS is the heterozygous mutation in the fumarate hydratase (FM) gene, described for the first time in the LMS of the skin, but similar genetic mutations have been found in the development of soft-tissue LMS. The mutation of FM gene has a familial inheritance, explaining the occurrence of soft-tissue sarcomas at a young age in homozygous individuals.

A critical role in cellular differentiation and the regulation of apoptosis has PRUNE2 protein, having higher expression in small-sized tumors and being down-regulated according to increased tumor volume. Zhao et al found that PRUNE2 expression was an independent prognostic factor for survival rates in patients with LMS, being associated with a good prognosis ${ }^{39}$.
Renal LMS with c-Myc expression was found to be associated with a poor prognosis by Tsiatis et $\mathrm{a}^{40}$.

In our experience, renal sarcomas accounted for $1.5 \%$ of malignant kidney tumors. Clinical manifestations were dominated by the presence of an abdominal mass, associated with systemic symptoms such as weight loss, asthenia and fever. Most of the patients had an advanced tumor stage at diagnosis, and despite complete surgical resection, they died in the first year following surgery.

In a clinical-pathological study of 27 cases of LMS, Miller et al found that the mean patients' age at diagnosis was 58.5 years, and that the majority were females, with a mean tumor size of $13.4 \mathrm{~cm}$. The tumors had a low mitotic activity, with an average extent of necrosis of $21 \%$. Direct extension beyond the kidney capsule was identified in $55 \%$ of the cases, and lymphovascular invasion was identified in $26 \%$. In terms of follow-up, metastases were identified in $90 \%$ of cases, and $75 \%$ of patients died from the disease. They concluded that LMS have a grim prognosis, regardless of the underlying histology ${ }^{41}$.

Xiong et al, in their retrospective review regarding primary LMS, had approximately the same result, supporting the findings of Miller et $\mathrm{a}^{142}$. Most of the patients were females, with a mean age of 45.7 years and a mean tumor size of $11.1 \mathrm{~cm}$. Half of the patients had direct invasion of the renal capsule, with lymphovascular invasion in only $23.1 \%$ of the cases. Most of the patients died in the first year following surgery, with $72 \%$ developing metastasis ${ }^{42}$.

A research on the imaging findings of primary renal sarcoma concluded that tumors originating from the mesenchymal cell had the characteristics of malignant tumors, but without histological specificity and could not be differentiated from $\mathrm{RCC}^{43}$. Seven cases of renal sarcoma were retrospectively reviewed, including 3 leiomyosarcoma and 1 for each of liposarcoma, fibrosarcoma, malignant fibrous histiocytoma and malignant Schwannoma. The authors found that the common presentation was that of a large mass with irregular margin, indefinite, circumscribed and heterogeneous in density, with necrosis inside, as observed on the CT. The enhanced CT and MRI are beneficial to the differential diagnosis and management, being more capable of providing useful information about the localization, changes in density/ signal and extent of invasion of the tumor ${ }^{43}$.

A retrospective analysis of primary renal sarcoma concluded that early diagnosis and radical nephrectomy can prolong patients' life. The time of survival varied from 7 to 132 months ${ }^{44}$.

Shirkhoda et al stated that the diagnosis of renal sarcoma should be suspected when CT findings suggest that the tumor arises from the renal capsule 
or renal sinus and when the tumor is hypovascular or avascular on angiogram. The characteristic negative attenuation values for liposarcomas allows a specific diagnosis. The most frequent presenting symptom in the 14 patients admitted into the study was an abdominal mass or pain ${ }^{45}$.

Two studies on the diagnosis and treatment of renal sarcoma had similar results ${ }^{46}$. The most common sign at presentation was abdominal mass and the predominant histologic subtype was leiomyosarcoma. In Wang et al study, approximately $15 \%$ of the patients had metastatic disease at diagnosis ${ }^{47}$. Most of the patients died in the first 3 years following surgery. They concluded that adult kidney sarcomas have a poor prognosis, clinically renal sarcomas are similar with advanced renal cell carcinoma and early diagnosis and surgical resection offer patients the best chance of survival ${ }^{46-49}$.

\section{Conclusions}

Renal sarcomas are exceedingly uncommon malignant tumors, with a very poor prognosis, being diagnosed predominantly in the $4^{\text {th }}$ to $6^{\text {th }}$ decade of life. The presence of an abdominal mass represented the most frequent clinical sign. The most important positive prognosis factor for these tumors is complete surgical excision, with negative margins. Other than surgical resection, tumor grade and size are also important prognostic factors. Sarcomas possess complex and "chaotic" genetic and molecular structures. Sarcomas of the kidney, compared with other urogenital sarcomas, have a lower survival rate. Renal sarcomas are hard to differentiate from RCC, but the differential diagnosis should be taken into account in the presence of a rapid growing renal mass without lymphadenopathy. Surgery is the main treatment modality for renal sarcomas.

\section{Compliance with Ethics Requirements:}

„The authors declare no conflict of interest regarding this article"

„No funding for this study"

\section{References}

1. Venkatesh K, Lamba Saini M, Niveditha SR, Krishnagiri C, Babu S. Primary leiomyosarcoma of the kidney. Patholog Res Int 2010; 2010:652398.

2. Lalwani N, Prasad SR, Vikram R, et al. Pediatric and adult primary sarcomas of the kidney: a cross-sectional imaging review. Acta Radiol 2011;52:448-457.

3. Valery JR, Tan W, Cortese C. Renal leiomyosarcoma: a diagnostic challenge. Case Rep Oncol Med 2013;2013:459282.
4. Lee G, Lee SY, Seo S, et al. Prognostic factors and clinical outcomes of urological soft tissue sarcomas. Korean J Urol 2011; 52:669-673.

5. Gutierrez JC, Perez EA, Franceschi D, et al. Outcomes for soft-tissue sarcoma in 8249 cases from a large state cancer registry. J Surg Res 2007;141:105-114.

6. Perez EA, Gutierrez JC, Moffat FL Jr, et al. Retroperitoneal and truncal sarcomas: prognosis depends upon type not location. Ann Surg Oncol 2007;14:1114-1122.

7. Niculae A, Peride I, Marinescu-Paninopol A, et al. Renal artery bilateral arteriosclerosis cause of resistant hypertension in hemodialysed patients. Romanian Journal of Morphology and Embryology 2016;57(2): 591-594 .

8. Checheriță IA, Smarandache D, Rădulescu D, et al. Calcific uremic arteriolopathy in hemodialyzed patients. Chirurgia 2013;108(5):736-40.

9. Radulescu D, Stroescu Balcangiu AE, Pricop C, et al. Vitamin K influence on cardiovascular mortality in chronic hemodialysed patients. Rev Chim 2017; 68(1):52-54.

10. Niculae A, Peride I, Vinereanu V, et al. Nephrotic syndrome secondary to amyloidosis in a patient with monoclonal gammopathy with renal significance (MGRS). Romanian Journal of Morphology and Embryology 2017; 58(3):1065-1068.

11. Diaconu CC, Manea M, Iancu MA, et al. Hyponatremia in patients with heart failure: a prognostic marker. Rev Chim 2018; 69(5): 1071-1074.

12. Diaconu CC, Stanescu AMA, Pantea Stoian A, et al. Hyperkalemia and cardiovascular diseases: new molecules for the treatment. Rev Chim 2018; 69(6):1367-1370.

13. Diaconu CC, Drăgoi CM, Bratu OG, et al. New approaches and perspectives for the pharmacological treatment of arterial hypertension. Farmacia 2018; 66(3): 408-415.

14. Diaconescu D, Pantea Stoian A, Socea LI, et al. Hepatorenal syndrome: a review. Arch Balk Med Union 2018;53(2):239-245.

15. Draghici T, Negreanu L, Bratu O, et al. Liver abnormalities in patients with heart failure. Arch Balk Med Union 2018;53(1):76-81.

16. Paraschiv B, Dediu G, Iancu A, Bratu O, Diaconu C. Superior vena cava syndrome. Arch Balk Med Union 2017;52(1):39-43.

17. Belciu D, Horodinschi RN, Ionescu C, Bratu OG, Diaconu CC. Right hemiplegia and dyspnea: What is the link between? Arch Balk Med Union 2017;52(3):353-358.

18. Constantinoiu S, Birla R, Iosif C, et al.Difficulties in diagnosis and surgical treatment of a giant retroperitoneal lipoma. Chirurgia 2009;104(3):363-367.

19. Marcu RD, Spinu AD, Socea B, et al. Castleman's disease clinical, histological and therapeutic features. Rev Chim 2018; 69(4):823-830.

20. Beardo P, José Ledo M, Jose Luis RC. Renal leiomyosarcoma. Rare Tumors 2013;5(3):e42.

21. Edge SB, Byrd DR, Compton CC, et al. AJCC Cancer Staging Manual. 7th edition. Springer; New York, NY: 2010. Soft tissue sarcoma: 291-296.

22. Lewis JJ, Leung D, Woodruff JM, Brennan MF. Retroperitoneal soft-tissue sarcoma: analysis of 500 patients treated and followed at a single institution. Ann Surg 1998;228:355-365.

23. Van Dalen T, Plooij JM, van Coevorden F, et al. Dutch Soft Tissue Sarcoma Group: long-term prognosis of primary retroperitoneal soft tissue sarcoma. Eur J Surg Oncol 2007:33:234-238.

24. Singer S, Maki RG, O'Sullivan B. Soft tissue sarcoma. In: DeVita VT Jr, Lawrence TS, Rosenberg SA, editors. Cancer: 
Principles and Practice of Oncology. 9th edition. Lippincott Williams \& Wilkins; Philadelphia, PA: 2011:1533-1577.

25. Öztürk H. Prognostic features of renal sarcomas (Review) Oncol Lett 2015;9(3):1034-1038.

26. Nagumo Y, Kimura T, Ichioka D, et al. Long-term survival with gemcitabine and docetaxel for renal leiomyosarcoma: a case report. Hinyokika Kiyo 2013;59:497-501.

27. Kamba T, Kawakita M, Noguchi T, et al. Neoadjuvant CYVADIC (cyclophosphamide, vincristine, adriamycin and dacarbazine) therapy for retroperitoneal leiomyosarcoma: a case report. Hinyokika Kiyo 1997;43:577-580.

28. Maki RG, Wathen JK, Patel SR, et al. Randomized phase II study of gemcitabine and docetaxel compared with gemcitabine alone in patients with metastatic soft tissue sarcomas: results of sarcoma alliance for research through collaboration study 002 [corrected]. J Clin Oncol 2007; 25:2755-2763.

29. Mazeron JJ, Suit HD. Lymph nodes as sites of metastases from sarcomas of soft tissue. Cancer 1987; 60:1800-1808.

30. Deyrup AT, Montgomery E, Fisher C. Leiomyosarcoma of the kidney: a clinicopathologic study. Am J Surg Pathol 2004; 28:178-182.

31. Iwasaki H, Fuse H, Imamura Y. Myeloid sarcoma of the kidney: a case report. Nihon Hinyokika Gakkai Zasshi 2012;103:708-711. (In Japanese)

32. Ellinger J, Bastian PJ, Hauser S, Biermann K, Müller SC. Primitive neuroectodermal tumor: rare, highly aggressive differential diagnosis in urologic malignancies. Urology 2006; 68:257-262.

33. Angel JR, Alfred A, Sakhuja A, et al. Ewing's sarcoma of the kidney. Int J Clin Oncol 2010; 15:314-318.

34. Zhang J, Liu B, Song N, et al. Interdigitating dendritic cell sarcoma presenting in the kidney combined with retroperitoneal leiomyosarcoma: a case report and literature review. Oncol Lett 2014;7:466-470.

35. Nayer H, Murphy KM, Hawkins AL, et al. Clonal cytogenetic abnormalities and BCL2 rearrangement in interdigitating dendritic cell sarcoma. Leuk Lymphoma 2006;47:2651-2654.

36. Hakverdi S, Güngören A, Yaldiz M, Hakverdi AU, Toprak S. Immunohistochemical analysis of $\mathrm{p} 16$ expression in uterine smooth muscle tumors. Eur J Gynaecol Oncol 2011;32:513515 .
37. Schwetye KE, Pfeifer JD, Duncavage EJ. MED12 exon 2 mutations in uterine and extrauterine smooth muscle tumors. Hum Pathol 2014; 45:65-70.

38. Silveira SM, Villacis RA, Marchi FA, et al. Genomic signatures predict poor outcome in undifferentiated pleomorphic sarcomas and leiomyosarcomas. PLoS One 2013;8:e67643.

39. Zhao LR, Tian W, Wang GW, Chen KX, Yang JL. The prognostic role of PRUNE2 in leiomyosarcoma. Chin J Cancer 2013; 32:648-652.

40. Tsiatis AC, Herceg ME, Keedy VL, et al. Prognostic significance of c-Myc expression in soft tissue leiomyosarcoma. Mod Pathol 2009; 22:1432-1438

41. Miller JS, Zhou M, Brimo F, Guo C, Epstein JI. Primary leiomyosarcoma of the kidney: a clinicopathologic study of 27 cases. The American Journal of Surgical Pathology 2010; 34(2):238-242.

42. Xiong ZB, Shi M, Kunwar A, et al.Primary leiomyosarcoma of the kidney: a clinicopathological study of 13 cases at a high-volume institution. Sichuan Da XueXue Bao Yi Xue Ban 2012;43(1):86-90.

43. Dai J, Li J, Liu Y. Imaging findings of primary sarcoma in the kidney. Zhonghua Zhong Liu Za Zhi 1998;20(2):137-9.

44. Lin J, Zhang XP, Huang BW, et al. Retrospective analysis of primary renal sarcoma: 17 cases report. Beijing Da XueXue Bao Yi Xue Ban 2013;18;45(4):554-7.

45. Shirkhoda A, Lewis E. Renal sarcoma and sarcomatoid renal cell carcinoma: CT and angiographic features. Radiology 1987;162(2):353-7.

46. Huang ZM, Li HZ, Ji ZG, Shi BB. Diagnosis and treatment of primary adult renal sarcoma. Chin Med Sci J 2011;26(3):172-4

47. Wang $X, X u$ R, Yan L, et al. Adult renal sarcoma: clinical features and survival in a series of patients treated at a high-volume institution. Urology 2011; 77(4):836-41.

48. Anghelache L, Marinescu B, Isvoranu G, Cringanu D, Niculae A, Bratu O. Cytostatic therapy on tumor bearing mice: biochemical and hematological aspects. Modern Medicine 2016; 23(1): 26-32.

49. Brătilă E, Ionescu OM, Berceanu C, Coroleucă CA, Ardeleanu CM, Mehedințu C. Vaginal epithelioid angiosarcoma: a rare case. Rom J Morphol Embryol 2016; 57(3):1131-1135. 